\title{
Could curiosity save lives? An exploration into the value of using professional curiosity and partnership work in safeguarding adults under the Care Act 2014.
}

\author{
Abstract \\ Purpose - The purpose of this paper is to consider the importance of professional curiosity and \\ partnership work in safeguarding adults from serious harm, abuse and neglect.
}

Design/methodology/approach -The paper draws on a range of materials including; review of published materials in relation to professional curiosity, reports from adult Serious Case Reviews (SCRs) and Safeguarding Adult Reviews (SARs); relevant materials drawn from the SAR Library, thematic reviews of SARs and Google searches; observations from practice and experience. It also refers to relevant academic literature.

Findings - Lessons from SCRs and SARs show that a lack of professional curiosity and poor coordination of support can lead to poor assessments and intervention measures that can fail to support those at risk of harm and abuse. There are a number of barriers to professionals practicing with curiosity. Working in partnership enhances the likelihood that professional curiosity will flourish.

Practical implications - There are clear implications for improving practice by increasing professional curiosity amongst professionals. The authors argue that there is scope to improve professional curiosity by utilising and developing existing partnerships, and ultimately to help reduce the number of deaths and incidents of serious harm.

Originality/value -The paper considers the importance of employing professional curiosity and partnership work in safeguarding adults' practice, so enabling practitioners to better safeguard adults at risk of abuse and neglect.

Keywords: Professional curiosity, partnership work, collaboration, safeguarding adults.

Paper type: Practice paper

\section{Introduction}

Professional curiosity and partnership work have been emerging themes, increasingly identified in learning from adult SCRs and SARs (Braye et al, 2017; Preston-Shoot, 2017). Whilst the notion of professional curiosity is not new in social work practice, limited literature on the subject exists in key adult social work texts and the broader literature. For example, although thematic reviews covering SARs on dementia and care home settings highlight the importance of partnership work through greater engagement with health, social work and care home staff, professional curiosity is not mentioned as a particular issue (Manthorpe and Martineau, 2016; 2017). In his analysis of SCRs and SARs, ( $n=37)$ relating to self-neglect between 2013 and July 2017, Preston-Shoot (2017) identified that failure to employ curiosity at both the individual direct practice level and organisational level led to failings to protect those in need of some support/assistance/protection from adult safeguarding. Braye et al (2017) also identified that practitioners often failed to employ 'concerned curiosity' when determining service user autonomy in self-neglect practice. A lack of curiosity has also been 
recognised for some time in serious case reviews when a child dies or is seriously harmed (Brandon et al, 2012). The reviews held following the high-profile deaths of Victoria Climbie, Peter Connelly and Daniel Pelka have all called for greater scrutiny and professional curiosity amongst professionals from statutory agencies. Yet there remains limited discussion of the skills needed to engage in professional curiosity practice in core social work textbooks and practice literature. Further, most lessons to be learned detailed in reports from SCRs and SARs highlight a lack of coordinated systems of support for those needing protection, as well as poor inter-professional and interagency collaboration by the agencies required to protect those in need of protection from abuse and neglect. In their analysis of SARs ( $n=27)$ Braye and Preston-Shoot (2017) identified that a lack of shared approaches to practice was a factor in 23 of the 27 SARs analysed, and issues with interagency communication and information sharing were factors in 23 of the 27 SARs. Stevens (2013) noted that: "in practice, differing professionals may not fully understand each other's roles and responsibilities and both thresholds and scope of adult abuse are still not universally agreed". Earlier, Perkins et al, $(2007$, p.9) commented that "resource pressures, insufficient information sharing and a lack of clarity about roles and responsibilities" hindered multi-agency work in this area. Whilst understanding the importance of working in partnership has deepened in recent years, evidence drawn from SARs frequently cites the need for greater partnership and more co-ordinated working in order to safeguard adults with care and support needs (Preston-Shoot, 2017).

This practice paper draws from a review of SARs and SCRs, which were accessed through the SAR library, reviews of SARs and Google searches, and a thematic analysis of the SARs reviewed that were relevant to the themes of this paper. The paper contributes to the body of knowledge in this area of practice by focusing on the relevance of professional curiosity and partnership work in safeguarding adults. It does so by drawing from the broad literature and observations from practice, including lessons to be learnt from a number of published SCRs and SARs. The discussion is contextualised in safeguarding adult practice, policies and law in England. However, the practice issues discussed have more universal application. Practitioners outside of England may wish to draw from the practice discussions and apply relevant content, taking into account the context of their own local and national policies and law.

\section{What is Professional curiosity?}

There is no clear definition of professional curiosity; most writers identify a number of characteristics associated with the term. Burton and Revell $(2018$, p. 1512) note that the notion of professional curiosity "appears to be assumed and lacking in clarity". Writing in relation to young people, Williams 
and Chisholm (2018, p.203) suggest being professionally curious entails: "asking questions that give and solicit information without being intrusive or making the [service user] feel threatened. These should be open-ended and allow for additional probing". Practice literature suggests that professional curiosity relates to the capacity and communication skills needed to explore and understand what is happening with an individual or family. It is about enquiring deeper and using proactive questioning and respectful challenge, understanding one's own responsibility and knowing when to act, rather than making assumptions or taking things at face value (Norfolk Safeguarding Adults Board 2018).

\section{Policy and legal context}

Engagement in practice that includes professional curiosity and partnership work is embedded in safeguarding adult policies and the Care Act 2014, the main statutory framework which guides safeguarding adult practice. It is expected within the British Association of Social Work Professional Capabilities Framework (PCF, 6) (BASW, 2018 p.26) that those entering social work education and the profession will: "apply imagination, creatively and curiosity to practice". Drawing from Peterson and Seligman's (2004) work, Sekerka et al, (2014, p 710) defined curiosity as: "a capacity to want to explore possibilities...choosing to seek out additional information, exploring and considering alternative views, and asking questions about the causes and conditions". The literature suggests curiosity involves engagement in exploratory behaviour to learn and it is held to be important in the context of complexity and uncertainty (Burton and Revell, 2018; Kedge and Appleby 2009). Burton and Revell (2018, p. 1512) suggest that: "curiosity is characterised by growth, exploration and development". A curious personality is linked to a range of adaptive behaviours, which include tolerance to unconventional thinking, the ability to adapt and a non-defensive and non-critical attitude (Kashdan et al, 2013). According to the literature, curious practitioners not only desire to learn but are keen to analyse what is being presented in order to know what might be happening, or what is expected but missing from what has been observed, in order to question what is presented (Burton and Revell, 2018; Kashdan et al, 2013). Kashdan and colleagues (2013, p. 142) also posit that curious people have: "predispositions to recognize and search for new knowledge". Understanding gaps in knowledge and having skill and confidence to employ respectful uncertainties, ie taking a sceptical approach (Laming, 2003) to what might happen, are essential to professionally curious practice. Litman (2005, p.793) notes that curiosity involves a: "desire to know, to see or to experience that motivates exploratory behaviour directed towards the acquisition of new information". Braye et al (2017) point out that in safeguarding practice, curiosity involves stepping outside institutional frameworks and procedures in order to effectively and appropriately engage in practice. Hafford-Letchfield and Carr (2017) also note 
that participation in curious behaviour involves deconstructing stereotypes that prevent the inclusion of service users and their carers voices within safeguarding adult practice.

Policy and practice indicate that it is by working in partnership that agencies can come together to share information about the people they work with, to gain a holistic picture and work collaboratively to make appropriate decisions and plans (Braye et al, 2017; Preston-Shoot, 2017). These are supported by lessons learned from SARs. Partnership is defined by Carnwell and Carson (2009, p.7) as: "a shared commitment, where all partners have a right and an obligation to participate and will be affected equally by the benefits and disadvantages arising from the partnership". Partnership working is seen as integral to safe practice, to the extent that the concern that partner agencies should work together more effectively to protect the individual is one of the Care Act 2014's criteria in relation to requiring a SAR to be carried out, in addition to the inclusion of the 'duty to cooperate' on safeguarding matters. Earlier research by Penhale et al, (2007), Perkins et al, (2007) and Petch (2008) supports effective partnership in safeguarding adult practice. In England, policy stipulates that safeguarding is everyone's business (DH, 2013). The Statutory Guidance accompanying the Care Act 2014 (DHSC 2018a, 14.12) obliges local authorities to develop strong multi-agency partnerships with other agencies in order to provide timely and effective preventative support to those at risk or who are experiencing abuse and neglect, whether they are receiving care and support or not. Public authorities are required to take a multi-agency approach to provide effective coordinated assessments and interventions to safeguard those at risk of abuse and neglect or those experiencing abuse (DHSC, 2018). The Care Act 2014 also mandates local authorities to work in partnership with others to achieve better outcomes for those at risk of abuse and neglect. Cooperation with others is incorporated in safeguarding adult practice and law to address poor information sharing, which has been identified in number of SCRs and SARs (Preston-Shoot, 2017). Section 6 and s.7 of the Care Act 2014 set out general and specific duties for local authorities and relevant partners to cooperate when exercising their duties under the Act. Local authorities are obligated under s.3 of the Act to integrate care and support with health services. Similar duties are placed on National Health Service (NHS) England and Clinical Commissioning Groups (CCGs) to promote integration with care and support in safeguarding adult practice. Further, section 42 (2) of the Care Act 2014 requires local authorities to make enquiries or cause other agencies to do so on their behalf in relation to safeguarding referrals or alerts. This is further extended under 5.43 of the Act, which requires local authorities to set up Safeguarding Adults Boards (SAB) at the local level. A SAB is made up of statutory and independent agencies and groups, local authority, CCGs and the police and including service users and carer representation. As well as having a strategic oversight to help protect and safeguard those at risk of abuse and neglect and those experiencing abuse and 
neglect, Boards have legal responsibilities to coordinate and determine what each member (including at organisational level) does in order to safeguard adults from abuse and neglect. In the UK, although abuse of adults at risk of harm has likely existed throughout history, development of policy and law including systems and structures supporting safeguarding adult practice has only taken place in the last twenty years and therefore it has historically lagged behind safeguarding children practice (Chisnell and Kelly, 2019).

\section{UK practice variation}

Further, whilst jurisdiction for safeguarding adults is different in the four countries that make up the UK, the principles of partnership and collaboration across agencies and disciplines in safeguarding adult practice is evident in the policies and practices in the four nations. For example, the Northern Ireland Adult Safeguarding Partnership (NIASP) and Local Adult Safeguarding Partnerships (LASPs) which provides strategic leadership and direction to agencies involved in adult safeguarding practice, includes different organisations and professionals in planning and delivery of safeguarding services. Similarly, in Scotland the Adult Support and Protection (Scotland) Act 2007 obliges local councils to take a multi-agency approach to safeguarding adults and co-operation is emphasised under section 42 of the 2007 Act. Further, lessons to be learnt from Significant Case Reviews (SCRs) in Scotland and Safeguarding Adult Practice Reviews (Wales) all stress the importance of co-operation and partnership working (Cornish and Preston-Shoot, 2013; Philips, 2016). The Welsh equivalent legislation to the Care Act 2014, the Social Services and Well-Being (Wales) Act 2014, places emphasis on joint working and there is also a duty to co-operate under section 135 (5) and (6).

In England, whilst the Care Act 2014 has, to some extent, had an impact in promoting information sharing, partnership work and collaboration, evidence drawn from reviews of SCRs and SARs suggests that: "typically weaknesses existed in all layers of the system, from individual interaction through to interagency governance, and beyond to the broader policy and economic context" (Preston-Shoot, 2017 p82). There are numerous blocks to practising in a professionally curious way; we seek to outline these, making links to published SCRs and SARs where issues relating to professionally curious practice have been identified as part of the learning. We also seek to make links between partnership working and professional curiosity, exploring whether a partnership approach can actually improve professional curiosity and as such, reduce risks to adults. The literature, together with observations drawn from practice suggests that factors inhibiting engagement in combining professional curiosity and partnership working include organisational demands, lack of resources, lack of support, time 
demands and the emotional intensity of safeguarding practice including emotional disconnection and confirmation bias (Preston-Shoot, 2017).

\section{Barriers to professional curiosity}

It is important to note that when a lack of professional curiosity is cited as a factor in a serious and harmful incident that has resulted in a review, it does not automatically mean that blame should be apportioned; indeed, the emphasis is on applicable learning, not blame. In what follows, we examine the blocks and barriers to developing appropriate levels of professional curiosity. Evidence from SARs and case examples are provided to illustrate how these blocks may have contributed to adverse incidents occurring and consideration is given to whether a partnership approach could have reduced the impact of the barriers. There is variation in the way the subjects of SARs are reported and the terminology used, and the names used in this paper reflect conventions used in reports. The discussion is structured around three overarching themes (and sub-themes) which emerged from the literature: "case dynamics", "professional issues" and "organisational issues".

\section{Case dynamics}

This theme relates to factors impacting on practitioners' engagement with the individual(s) experiencing or at risk of harm, their family, carers or other interested parties. Sub-themes identified under case dynamics include: "disguised compliance" "knowing but not knowing", and "accumulating risk".

\section{Disguised compliance}

The literature suggests that disguised compliance occurs when a family member or carer gives the appearance of co-operating with professionals to avoid raising suspicions, to allay professional concerns and ultimately to reduce professional involvement (Stevens et al, 2017). To recognise and challenge disguised compliance, professionals need to establish facts and gather evidence about what is actually happening, and the focus must be on outcomes rather than processes to ensure that practitioners remain person-centred. Evidence drawn from one SAR relating to disguised compliance is that of Adult $\mathrm{H}$ (Ohdedar, 2017). Adult $\mathrm{H}$, aged 21 at the time of the incident that resulted in the review, had a diagnosis of Spina Bifida and Hydrocephalus. A safeguarding adult referral was made by the ambulance service following severe burns. Adult $\mathrm{H}$ suffered $14 \%$ skin loss and chronic wounds indicative of urine burns. Adult $\mathrm{H}^{\prime} \mathrm{s}$ transition from child services to adult care showed minimal multiagency working. There was insufficient focus on non-attendance at medical appointments. The family's overall lack of engagement repeatedly disabled the safeguarding process, with no escalation 
by professionals. Adult $\mathrm{H}$ was consistently seen with her mother and lack of her own voice was apparent. Recommendations arising from this SAR included a review of case transfer between children's and adult's services, the creation of a multi-agency self-neglect policy, a multi-agency escalation policy, and guidance on what to do when services are consistently refused.

Another high profile example of disguised compliance occurred in the case of Peter Connelly (Haringey Safeguarding Children Board, 2009), a 17 month old child who died following extensive abuse. Peter's mother, her boyfriend and his friend were convicted of causing or allowing the death of a child. It is noted in the summary report that "Peter's face was smeared with chocolate and the social worker asked that it be cleaned off. The family friend took him away to do so and he did not reappear before the social worker left" (Haringey Safeguarding Children Board 2009, p.13). There is a suggestion that the chocolate around the toddler's mouth had been placed there by the family to conceal an injury. The social worker had begun to check for disguised compliance (i.e. that the family was suggesting they were taking care of the child when in fact he had sustained another injury), but this opportunity was missed as he was removed before his face could be properly checked.

\section{'Knowing but not knowing'}

In contrast, the theme "knowing but not knowing" relates to having a sense that something is not right but not knowing exactly what it is, and so it is difficult to fully grasp the problem and take relevant action. Whilst on placement, and in discussion with a Practice Educator, a student social worker described a case where she worked with a service user who had been subject to domestic violence but had said that she [service user] had left her abusive partner. The student visited late on a winter's afternoon to review the care and support plan. She described that the house was dark, and the service user refused to put the light on, saying she was worried about the electricity bill. The student thought she could hear someone moving around upstairs despite the service user saying she was alone. The student reported she felt uncertain about this and left the property without enquiring further. She was able to reflect on this incident later in supervision, indicating that her anxiety in the moment had prevented her from being curious and respectfully challenging what had been said and felt both during and after the visit. As with disguised compliance, employing professional curiosity means seeking evidence to support or refute any concerns experienced.

\section{Accumulating risk}

As with the above, "accumulating risk", also identified as a sub-theme under "case dynamics", occurs when professionals respond to each situation or new risk discretely, rather than assessing the new 
information within the context of the whole person or looking at the cumulative effect of a series of incidents and information and seeing the whole picture (Braye et al, 2017; Preston-Shoot, 2017). A SAR providing an example of where professionals failed to assess accumulating risk factors is found in the Lancashire Safeguarding Adults Board SAR concerning Adult A (Chapman, 2017). This case related to $\mathrm{Mr}$ and $\mathrm{Mrs} \mathrm{A}$ who both showed signs of cognitive decline. Mr A exhibited paranoid tendencies, sometimes believing that his wife was an 'imposter'. He was also described by family as 'difficult' at times. Between 2011 and 2015, it was reported that the situation deteriorated, and the frequency and intensity of harmful or potentially harmful incidents involving Mrs A increased. The review described an episode when a graze was discovered on Mrs A's leg. Mrs A initially said she could not recall the incident occurring, but later said it was sustained when her husband threw a paper knife at her. A few weeks later, Mrs A was admitted to hospital with a severe head injury that she said she incurred when $\mathrm{Mr} A$ threw her across a table. Following her death, although a post mortem did not establish how the traumatic injury had occurred, it did conclude that the head injury had contributed to Mrs A's death (Chapman, 2017).

\section{Rule of optimism}

The 'rule of optimism' is a well-known dynamic in which professionals tend to rationalise away new or escalating risks despite clear evidence to the contrary. Risk enablement is about a strengths-based approach, but this does not mean that new or escalating risks should not be treated seriously. The review referred to in the last section concluded that greater curiosity should have been shown at the point that Mrs A sustained her leg injury. A number of concerns had been raised about Mr and Mrs A over a 5-year period, but they were always assessed as constituting low risk. The frequency of the incidents and escalation (at the point of the paper knife incident) were each assessed separately rather than in the context of an overall, escalating picture. There is a suggestion that practitioners had failed to spot the accumulating risk because they optimistically believed that the overall risk to Mrs A was low since each incident was individually assessed as low risk. The independent reviewer considered that the paper knife incident could have been a trigger for further exploration (Chapman, 2017), but because those involved believed there was a low risk of harm, further investigation did not take place although this would have been appropriate. A review of records and development of a case history could have led to a more robust analysis and understanding of the risks and consideration of the need for a more formal safeguarding response.

\section{Professional issues}


The theme "professional issues" relates to perceptions and attitudes of individual professionals involved in adult safeguarding practice. Sub-themes emerging under this theme include: "normalisation", "professional deference", "confirmation bias", "a lack of confidence in managing tension and dealing with uncertainty"

\section{Normalisation}

Normalisation refers to the social processes through which ideas and actions come to be seen as 'normal' and become taken-for-granted or viewed as 'natural' in everyday life. As they are seen as 'normal' they cease to be questioned. In safeguarding adult practice, when this occurs, potential risk factors are not (fully) recognised and therefore not assessed. A case example of where normalisation occurred is found in the SAR of a woman known as Mrs BB, undertaken by Norfolk Safeguarding Adults Board (Brabbs, 2016). Mrs BB was an older woman with dementia who frequently walked around the town where she lived, including going to visit her husband who resided in a local care home. She regularly became lost and asked for lifts and help to cross the road. The Police were often involved in returning her home, but these incidents were not reported to Adult Social Services. Unfortunately, Mrs BB left her home one cold winter's night and fell into a ditch where she died (Brabbs, 2016). Her walking behaviour was seen as 'normal' for her and was not put in the context of her holistic situation. This would have included, for example, having a diagnosis of dementia, and the risks related to 'wandering' and getting lost (we shall return to Mrs BB later in the paper).

\section{Professional deference}

A related theme is "professional deference". Good practice and the principles underpinning prevention in safeguarding adult practice require that professionals who have the most contact with those at risk or experiencing abuse and neglect are in a good position to recognise when the risks to the person are escalating and can provide appropriate support. However, evidence from practice suggests there can be a tendency to defer to the opinion of a 'higher status' professional who has had limited contact with the person. In one case example drawn from practice, a safeguarding strategy meeting was convened concerning an unnamed nursing home. It was concluded that the care provision was not good enough, but the provider had put measures in place to make improvements. Despite these measures, the General Practitioner (GP) covering the nursing home continued to believe that the patients in the provider unit were unsafe. The risks to the residents from staying at the provider unit, which was making improvements but where the quality of care was still of concern, were weighed against the risk to residents from the distress caused by a move. All professionals, other than the GP, believed the risks from such a move outweighed the risks to the residents of remaining at the provider 
unit, which was still making improvements. However, in the absence of a formal escalation route, the GP decided to email local Member of Parliaments (MPs) and the Chief Executive of the local CCG, expressing and escalating concerns about what the GP perceived as the risks to the people receiving nursing care in the unit. The MPs and Chief Executive were far removed from the details of the case and therefore unable to express a view, having to pass the concerns to other senior managers. The senior managers deferred to the GP as the highest status professional involved and gave more weight to the GP's concerns than to the suggested mitigating actions put forward by Social Workers and Quality Assurance Officers. The matter escalated rapidly and significantly to the point where the provider made the decision that they did not wish to continue to run the unit any longer and would cease operations. As a result, around 25 people had to move out of their home to alternative provision. This example illustrates how senior managers in health and social care had deferred to the view of a GP as a senior medical professional, despite the more measured views of other professionals involved.

Examples of professional deference can also be seen routinely in practice in hospital settings where it has historically been traditional for medical consultants to 'prescribe' residential care services for people ready to leave hospital. The implementation of the Care Act 2014, and introduction of strengths-based assessment models, have reduced the impact of this practice, but it has traditionally been extremely difficult for Social Workers to advocate for an adult's right to return home, when a consultant has already set an expectation with family members and other professionals that another form of care setting is what is required for the individual..

\section{Confirmation bias}

Another sub-theme emerging under "professional issues" is "confirmation bias", which relates to the practice of looking for evidence that supports or confirms one's pre-held views, ideas and values, and ignoring contrary information that refutes them. Observations from practice, and evidence drawn from a number of SARs suggest that confirmation bias occurs when we filter out potentially useful facts and opinions that do not match our preconceived ideas. When this happens, thinking around a case becomes 'fixed' and there is a lack of openness to new knowledge that could alter the established paradigm. A SAR published by West Sussex Safeguarding Adults Board (Boxall, 2018), concerning Matthew Bates and Gary Lewis aged 30 and 63 respectively, with profound learning disabilities, cerebral palsy and osteoporosis, is one example where confirmation bias occurred. Both men were resident in the same residential care home in West Sussex, and both were admitted to hospital and found to have suffered fractures to their femurs. An assumption was made that the injuries were due to a moving and handling issue and no safeguarding referral was raised. The SAR concluded that the 
circumstances of these injuries and a consultant's statement should have led to the police being contacted directly by the hospital. The SAR report also suggests that at an early stage moving and handling was the emerging explanation, and this was never strongly challenged or alternative explanations sought. Confirmation basis appears to have reduced professional curiosity in this case, leading to a lack of consideration of other possibilities. The SAR concluded that had the injuries occurred to two children, it is more than likely that police would have been contacted by hospital staff for further investigation (Boxall, 2018).

\section{Lack of confidence in managing tension and dealing with uncertainty}

Another sub-theme to emerge under "professional issues" is "a lack of confidence in managing tension", which inhibits curiosity. Stevens et al (2017) found that disagreement, disruption and aggression from families or others, can undermine confidence and divert meetings away from topics that practitioners want to explore in more depth. The authors also found that dealing with uncertainty can undermine professional curiosity (Stevens et al, 2017). Contested accounts, vague or retracted disclosures, deception and inconclusive medical evidence are commonly found in safeguarding practice. Practitioners are often presented with concerns which are impossible to substantiate. In such situations, there could be a temptation to ignore concerns that cannot be substantiated. A personcentred approach requires practitioners to remain mindful of the original concern and to be professionally curious. An example of this is seen in a SAR that was carried out by Solihull Safeguarding Adults Board (2017) concerning a man named John, who was 37. At the time of the review, he lived with his mother and stepfather, having been removed from residential care by them. Reports outlining the circumstances in which this occurred were unavailable. John's stepfather was a 'Schedule 1 offender' who had been convicted of murder in 1984, serving 20 years in prison. John received home support from an agency, but this ceased after 2 months. Concerns were expressed about John's mother's ability to care for him, that she was physically and verbally aggressive towards him and that she was misusing his direct payments. Further concerns were received in relation to physical, emotional and domestic abuse from John's stepfather and one of his brothers. During the enquiry John's sisters raised a further concern that John had been seriously sexually abused by his step-father. This case highlights the tensions and uncertainties of working with difficult, dangerous and evasive people and families, as well as with coercive and controlling behaviour. The review concluded that greater professional curiosity in day to day work with John, to ascertain what was happening in this family, and what John's 'lived' experience was, might have identified concerns when dealing with an apparently un-associated issue. 


\section{Organisational issues}

The key theme, "organisational issues" relates to factors such as inadequate supervision and lack of management oversight and security (Braye et al, 2017; Preston-Shoot, 2017).

\section{Inadequate supervision across agencies}

In Newcastle Safeguarding Adults Board's SAR, relating to Lee Irving, a 24 year old man with care and support needs who died following a disability hate related beating, the reviewer summarised that: "the relationship between Lee Irving and his killers was described as one of subservience with Lee beholden to the primary perpetrator for drugs and shelter and where Lee looked up to the primary perpetrator and, desperate to fit in, tolerated continued violence and abuse. This coercion and drugging were used to control him, prevent him seeking help" (Wood 2017, 1.2.5). The review concluded that whilst individual agencies had tried to engage with Lee there was not a coordinated information sharing response to the presenting issues, and there had been a lack of professional challenge. The findings also suggest that there were communication difficulties between agencies (Wood 2017). Notwithstanding this, good supervision should have ensured the continuity of high quality service. In another SAR, undertaken by Somerset Safeguarding Adults Board, (Flynn, 2016), $\mathrm{Tom}_{2}$ a 43 year old man with brain injuries, who took his own life, was reported to have been depressed, could not sleep, abused alcohol and drugs and had expressed his intention to take his own life but was considered ineligible for any mental health service provision. His family commented that professionals missed the subtleties of his condition by only dealing with parts of the problem, but no one professional had put the whole picture together. The SAR pointed out that: "the assessment processes experienced by Tom were not integrated and had no impact on inter-professional work" (Flynn 2016, p.24). Participation in reflective supervision would have supported professionals in any of the agencies concerned to consider this case from a number of different perspectives and could have increased the likelihood of a holistic picture emerging. The recently published Post Qualifying Standards for Social Work Practice Supervisors in Adult Social Care (DHSC 2018, p.12) describe supervision as: '... a regular and ongoing process involving a practice supervisor who has responsibility for overseeing the social worker's professional practice. It should take place regularly, usually as a one to one meeting, in an environment in which confidential discussions can take place... Supervision includes attending to managerial and performance functions, promoting professional development (including supporting the development of professional development plans) and supporting workers personally and emotionally and in developing resilience.' Supervision is a planned, accountable, twoway process, which supports, motivates and enables the development of good practice for individual social care workers. Further emphasis in the standards is placed on critical reflection. Lyn Romeo, the 
Chief Social Worker for England, blogged that: “...while management approaches to supervision are widely understood and applied, critically reflective supervision - where social workers are encouraged to reflect on the relationships and personal interactions between the social worker and the person or family they are supporting and making sure they are using approaches that work - remains less well established" (Romeo, 2018).

\section{Changes of practitioner}

The effects of limited resources such as changes in practitioner, resulting in repeatedly 'starting again' also emerged as a sub-theme under organisational issues that can hinder professional curiosity. Research suggests people who self-neglect require consistency, time to build a relationship and develop trust with their social worker (Anka et al, 2017; Braye et al, 2014). However, the high turnover of social workers has been shown to impact on the ability to develop relationships over time. A SCR relating to $\mathrm{Mr} \mathrm{BC}$ a 72 year old man, who died in a house fire, found that whilst over several years the same social worker undertook case reviews for $\mathrm{Mr} B C$, there was little evidence of ongoing visits between reviews, other than when triggered by a crisis of some sort (Braye et al, 2016). Mr BC lived in sheltered housing and had a package of care provided by Adult Social Services and was supported by his adult children. He was a heavy smoker and drank large amounts of alcohol. He was reported as reluctant to engage with services that tried to support him. Practitioner interactions with $\mathrm{Mr} B C$ focused on practical matters over which he required support, rather than on building a relationship that sought his perspectives on the reasons for his behaviour (Braye et al, 2016). The lack of continued contact with a social worker might have arisen due to the way Adult Social Care practice was previously structured in that cases were either closed or lay dormant until a review or crisis arose. Current practice approaches: strength-based model (DHSC, 2018), Making Safeguarding Personal (Lawson, 2017), and the-three conversations (Social Care Institute for Excellence , 2017), which aim to build relationships of trust with service users, by frequently seeking the personal desired outcome and involving them, should also encourage practitioner participation in employing curiosity and partnership work.

\section{Pressure and complexity of work}

Evidence drawn from other SCRs and SARs suggests that in adult self-neglect practice, practitioners often struggle to manage the tensions between respect for autonomy, self-determination and the legal obligations to safeguard and protect, which can then result in practitioners failing to employ respectful challenge and concerned curiosity (Braye et al, 2017). Similarly, evidence from SCRs and SARs suggests that practitioners' abilities to demonstrate professional curiosity can be hindered 
through pressure of work or complexity of cases. In the case of Mrs BB (Brabbs, 2016, already outlined), the practitioner involved in the case was found to have had an above average caseload, which led to the case being given insufficient priority and of concerns not being responded to in a timely way.

Closely linked to the above are situations in which practitioners close cases too early. A practitioner is unlikely to be motivated to follow up on new information or explore particular issues deeply if they know they will need to close the case quickly in order to deal with other demands from their caseload or new referrals. A hurried approach is sufficient to leave a person feeling that the worker does not want to hear any more. A case example of this is found in the SAR concerning Beryl Simpson, aged 82 years (Pearce, 2018). Beryl lived with her daughter aged 62 years, in a house that Beryl owned. On 6 December 2016, following concerns raised by Kent County Council Adult Social Care and Health (ASCH) about Beryl's welfare, Kent Police used their power under Section 17 of the Police and Criminal Evidence Act 1984 to enter the house. They found Beryl in a very poor state of health; she was emaciated and malnourished. Her daughter, Margaret, was also present in the house, which was in poor repair. There was no working toilet, it was cold and there was evidence of long-term extreme hoarding. After Beryl's condition was stabilised by paramedics, she was taken to hospital. Despite intensive treatment she died in hospital on 15 December 2016. The SAR report concluded that: 'the fundamental issue in this review is that organisations did not have any contact with Beryl in the last four and a half years of her life. While it is accepted that it will always be challenging to support people who decline help, there seems to have been a lack of what has become known as 'professional curiosity' about Beryl's condition (Pearce 2018, p.9). There is little evidence that, when contact was made in the initial stages with Beryl and Margaret, and latterly with Margaret, any questions were asked about Beryl's health and wellbeing. The report went further in suggesting that although Margaret was permitted to speak for Beryl, she was not asked about Beryl (Pearce, 2018). There was no evidence that Beryl lacked the mental capacity to make decisions for herself and in this case it was considered that more effort should have been made to speak to her. Similarly, the SAR relating to Adult C (Mellor, undated report) carried out by South Tyneside Safeguarding Adults Board concluded that: 'investing in building a relationship where Adult $\mathrm{C}$ might have been prepared to disclose what had happened in his life which had led to the circumstances in which he now found himself, [may have been achieved by] more consistent engagement by South Tyneside Council [if the Council followed a practice model] in which premature case closure was avoided' (p.35).

\section{Lack of professional curiosity at a strategic level}


Further, SARs concerning widespread abuse in provider settings highlight problems with professional curiosity at a more strategic/organisational level. A SAR commissioned by Somerset Safeguarding Adults Board (SSAB) following a safeguarding enquiry into allegations of the mistreatment of residents living at Mendip House, a care home for adults with autism run by the National Autistic Society (NAS), established that none of the people living at Mendip House were originally Somerset residents and that all were placed outside of their county of origin, often many miles from their families and communities (Flynn, 2018). The SAR also found that reviews by commissioners were often insufficiently robust, leaving the residents open to abuse due to inadequate monitoring of their care. Neither the history of safeguarding referrals nor Care Quality Commission (CQC) inspections revealed the cruelty of employees or the apparent failures of management oversight. Further evidence of a lack of professional curiosity or scrutiny at a strategic/organisational level is also evidenced in West Sussex Adult Safeguarding Board, SCR of Orchid View, which identified widespread abusive and neglectful practices in a care home for older people (Georgiou, 2014). The Coroner overseeing the inquest of a resident questioned a CQC inspection which gave Orchid View a 'good' rating in 2010 - a year before the home closed as 'unfit for purpose'. The SCR identified that safeguarding referrals were not raised or responded to appropriately by the provider, and that the CQC's inspection was not reflective of the serious concerns identified at the inquiry that was held. An apparent lack of curiosity among commissioners/providers/CQC seems to have been a factor in the incidents that occurred in both Mendip House and Orchid View. Neither the voices of the residents nor their representatives appear to have been heard, seemingly indicating a multitude of blocks to professional curiosity (disguised compliance, failing to spot accumulating risk, rule of optimism, confirmation bias, alongside working practices that were not conducive to concerned curiosity) at the strategic and organisational level as well as at more operational levels.

\section{The value of partnership working}

Measures enabling effective collaboration and partnership work identified by Petch (2008) and Julian and Penhale (2009), which are still relevant, include identification of a lead point of contact, clear, understood procedures and protocols for information sharing, senior management level commitment, shared budgets, multi-agency training, mutual respect, identified and agreed outcomes, and a focus on the person at the heart of the inquiry. This concurs with recent analysis of SCRs and SARs by Preston-Shoot (2017) and Braye et al, (2017). Since the introduction of the General Data Protection Act 2018, some agencies have become less willing to share information, even with regard to safeguarding cases, making the need for robust information sharing protocols, with senior management support, critical. The key policy in safeguarding adults, Making Safeguarding Personal 
supports the focus on the person at the heart of safeguarding adult enquiries and requires that practice is led and informed by the person's desired outcomes (Lawson, 2017). Key elements of partnership work go beyond information sharing and procedures, to include a greater focus on the relationships and interactions among partner agencies and individuals. Cooper (2018), building on the findings from Petch's (2008) work notes that partnership work should include:

- a shared overarching purpose (which adds value), objectives and aims;

- shared values, principles (including clarity, openness, trust) and goals;

- trusting relationships;

- regular communication (vertical and horizontal);

- understanding issues from different perspectives to develop 'joined up thinking', understanding each other, diversity and dynamism;

- mutual understanding of the value of each partner's contribution;

- acknowledgement of imbalances of power, access to resources, knowledge and understanding of issues;

- participation and engagement by all members;

- co-ordination, leadership and facilitation;

- reflection - monitoring and evaluating to show what works;

- positivity.

However, notions of the 'nanny state' and professionals as 'interfering busybodies' (see also Mantell and Jennings, 2016), which are often perpetuated by the media, can threaten professional curiosity and partnership working, leaving practitioners concerned that questioning too closely will feed these stereotypes.

\section{Future practice development}

For Social Workers, the need to draw from the values and principles that guide social work practice in safeguarding adults is important. These include for example, ensuring that the human rights of service users are respected, developing and building relationships of trust with service users, promoting equality, fairness, self-determination, respect for autonomy, challenging injustice and having a clear focus on the duty of care owed to those in need of protection from abuse and harm. Chisnell and Kelly $(2019$, p. 221) point out that: "as a profession social work is about "speaking truth to power" and this involves resisting policies and practice that could degrade and cause harm to people. The authors urge practitioners to move beyond a separatist approach in safeguarding practice by developing knowledge and skills needed for effective responses to individual needs across the lifespan (Chisnell and Kelly, 
2019). As mentioned previously, curiosity is linked to learning, development and growth, the essence of effective SCRs and SARs is about learning. The literature highlights the need for practitioners to carry out good assessments; early identification and assessment of risk are emphasised as are information sharing and targeted multi-agency interventions (DHSC, 2018). The Statutory Guidance Accompanying the Care Act 2014 stipulates that assessments and interventions should reflect the six safeguarding principles: empowerment, prevention, proportionality, protection, partnership, and accountability (DHSC, 2018) and this applies across all sectors and settings. A thorough assessment underpinned by these key guiding principles of safeguarding must foreground the wishes, aspirations and desired outcomes of those needing protection by identifying and addressing repeating patterns of risk and seeking further information from other agencies involved with the person needing safeguarding and protection (Chisnell and Kelly, 2019). To give one example, there is a need for greater awareness and understanding of the implications of traumatic brain injuries across health and social care services. Hospital discharge planning and community support services need to be more flexible in identifying and meeting the needs of patients with traumatic brain injury, and such agencies need to work together more (and more effectively) as required by s.3 and s.6 of the Care Act 2014 . Additionally, there is no substitute for "professional curiosity" in order to ensure that assessments are holistic, that services are appropriate and that multi-agency working is effective, as indicated in a professional response concerning the SAR on Tom, already referred to (Morgan, 2017).

Preston-Shoot (2017) points out that practitioners should not be tempted to close cases too quickly when those owed the duty of protection refuse support; rather, practitioners should employ curiosity by assessing the full extent of the person's vulnerability and appropriate support - both that which is available and that which might be acceptable and appropriate for the person. A sound knowledge of law and being culturally competent are also required in effective safeguarding practice with those from minority ethnic groups, as evidenced in the Laming Inquiry into the death of Victoria Climbie (Laming, 2003). The need to carry out mental capacity assessments, involving family members in assessments and interventions or challenging family members when necessary are also emphasised. One group of people ignored in policy are those who self-fund their care, Manthorpe and Martineau (2016; 2017) review of SCRs in care homes and dementia identified a key need for social work assessment and regular reviews of those who fund their own care. Manthorpe and Martineau (2016; 2017) suggest that in the context of inter-professional safeguarding practice, social work engagement with other professionals such as the police and care home staff is of importance. SCRs and SARs identify other core values in inter-agency safeguarding adult practice to include accountability and 
case ownership. Identifying a lead person to co-ordinate assessment and intervention of those needing safeguarding and protection are also crucial (Preston-Shoot, 2017).

Strengthening safeguarding partnerships and partnership working and promoting an integrated partnership approach will reduce the number and impact of the blocks and barriers to, and increase the likelihood of professionally curious approaches occurring within safeguarding adults work. For example, in the case of John (Solihull Safeguarding Adults Board 2017, discussed earlier), where there was much uncertainty and a fragmented approach, regular meetings of all multi-disciplinary professionals, with an identified lead professional, could have helped to collate the observations and perspectives of all those concerned to uncover disguised compliance, triangulate information from a range of professionals, seek confirmation of information presented, and consider different theories or research evidence in order to understand the situation. Similarly, a joined-up approach could have increased the confidence of the professionals involved to deal with conflict and uncertainty. Working closely with trusted professionals from different backgrounds and agencies will strengthen reflective practice. In the case of Lee Irving (Wood, 2017) better partnership relationships could have provided the confidence to enable professional challenge between agencies, using management structures to combat professional deference. Practice observations have shown that professionals with different skillsets, training and value bases, bring different perspectives, which provide a natural challenge and guard against the rule of optimism and the process of normalisation. For example, in the case of Mrs BB (Brabbs, 2016), had partners come together to discuss the levels of risk and share information, it is likely that someone would have identified the accumulating risks from walking and getting lost on a regular basis. Working as part of a team reduces the risks from individuals whose professional curiosity is reduced due to pressure, tiredness and/or burn-out. Similarly, implementation of careful risk assessments and contingency plans requires good management oversight, as with closure of cases in line with findings from SCRs and SARs (Preston-Shoot, 2017).

\section{Conclusion}

To conclude, this paper has reviewed the published material in relation to professional curiosity, and has made specific links to published SARs and SCRs where a lack of professional curiosity has been found to be a factor in incidents of serious harm or death, and we have demonstrated how professional curiosity is an important factor enabling professionals to safeguard adults at risk of abuse and neglect. SCRs and SARs have shown that a lack of professional curiosity and partnership work can lead to poor assessments and a failure to implement measures that can support those at risk of harm 
and abuse. This paper has demonstrated there are clear implications for improving practice. Some suggestions on possible ways forward are offered. As mentioned previously, partnership approaches offer a useful framework for strengthening professionally curious practice in safeguarding adults. Earlier research by Penhale et al, (2007), Perkins et al, (2007) and Petch (2008) supports effective partnership working in safeguarding adults. We have identified evidence to suggest that working appropriately in partnership with others increases the likelihood that professional curiosity will flourish.

The paper has drawn together examples of barriers to professionally curious practice and has suggested ways to develop the skills required to practice in this way, such as communication skills to support a deeper process of enquiry, risk assessment to identify and quantify risks, accurate recording and checking of records to identify cumulative risk, exploring networks and consulting widely with family members and professionals to gather a range of views, and the ongoing development and use of reflective/analytical skills to help us to understand complex situations or seek further information. This has been explored in more detail by Thacker (2018), and Manchester Safeguarding Adults Board (2018) which has also developed resources for different professionals, including a professionally curious and culturally competent safeguarding practice guide.

Research and practice indicate that structurally, partnership approaches are in place in the majority of local areas in England (Braye et al, 2017). However, despite the existence of such structures, there remains concern that professional curiosity is not occurring consistently, as evidenced by the continuing and relatively large number of SARs and SCRs that have identified its absence as a clear factor in incidents of serious harm or death. It is our view that further work is required to strengthen professional curiosity in partnership arrangements. Professional curiosity is a theme covered in some Social Work courses, but we conclude that this is an important topic that should be covered in all health and social care professional training programmes, including those for medical doctors. Relevant training in this area should also be provided for senior professionals. The Social Care Institute for Excellence has also noted that participation in continuing professional development programmes, which include keeping up to date with various professional and practice guidance would help to address a lack of professional curiosity and could also assist in the development of partnership working (Social Care Institute for Excellence, 2017).

Safeguarding Board Chairs and Board Managers can also play a role in strengthening partnership working and enhancing professional curiosity in their local areas by encouraging partnership 
discussion beyond board meetings, setting up local joint events where practitioners from different disciplines can meet and discuss relevant topics. Involvement of service user voices is crucial at such meetings. This would allow opportunity to discuss professional differences and value bases and most importantly enable practitioners to learn from service users' experiences.

In addition, professional curiosity across partnerships could be further supported by Safeguarding Boards which develop and oversee procedures to facilitate professional challenge, together with the management of complex cases and management of professional difficulties. Further, good quality supervision that allows sufficient time for, and encourages reflective practice is another important factor to create an environment in which professional curiosity can develop and be positively fostered.

Professional curiosity is a theme that arises with increasing frequency in SARs and SCRs. The purpose of these reviews is learning, and the outcome is that recommendations are made which local systems have to implement. While it is beyond the scope of this paper to look at how recommendations are put into practice, it is noted that as a result of the SAR for Mrs BB, Local Authority supervision practice was reviewed and a new procedure implemented, multi-agency complex case guidance was developed and published to support the partnership to come together to discuss cases where there were concerns but other formal partnership frameworks might not be applicable, and guidance on cumulative/escalating risk in dementia cases was developed, amongst other actions. More generally, working in partnership with colleagues from health organisations has led to the development of, for example, pressure ulcer pathways and medication incident decision pathways to develop a shared understanding across the local partnership area about when these issues need further investigation, and joint work with Police colleagues has led to referrals being sent to the most appropriate service the first time (for example if a primary need is for mental health, the case can go directly from Police to the local Mental Health Trust). It is notable that some local authorities are identifying professional curiosity as a key theme when developing and implementing care plans. Both Norfolk Safeguarding Adults and Safeguarding Children's Boards have identified professional curiosity as one of four key recommendation themes on their composite action plans.

The authors believe that there is scope to improve professional curiosity by utilising and developing existing partnerships, to help reduce the number of deaths and incidents of serious harm. We have made some suggestions about how this could be taken forward and also consider that further research should explore the success of a variety of approaches to improve skill development in professional curiosity and respectful challenge amongst health and social care professionals. 


\section{References}

Anka, A., Sorensen, P., Brandon, M. and Bailey, S. (2017), "Social work intervention with adults who self-neglect in England: responding to the Care Act 2014", The Journal of Adult Protection, Vol. 19 No. 2, pp. 67-77, doi.org/10.1108/JAP-11-2016-0027.

Boxall, B. (2018), Safeguarding Adult Review In respect of Matthew Bates and Gary Lewis, West Sussex Safeguarding Adults Board, Worthing.

Brabbs, C. (2016), Independent Overview Report of Mrs BB. Norfolk Safeguarding Adults Board, Norwich.

Brandon, M., Sidebotham, P., Bailey, S., Belderson, P., Hawley, C., Ellis, C. and Megson, M. (2012), New learning from serious case reviews: a two-year report for 2009-2011, Norwich: University of East Anglia and University of Warwick.

Braye. S., Orr, D., and Preston-Shoot, M. (2014), Self-Neglect Policy and Practice: Building an Evidence Base for Adult Social Care, London, available at: http://www.scie.org.uk/publications/reports/69-self-neglect-policy-practice-building-anevidence-base-for-adult-social-care/ (accessed $12^{\text {th }}$ Feb 2019).

Braye, S. (2016), Safeguarding Adults Review of the circumstances concerning Mr BC, Overview Report, Hackney Safeguarding Adults Board, London.

Braye, S., Orr, D., and Preston-Shoot, M. (2017), "Autonomy and Protection in Self-neglect Work: The Ethical Complexity of Decision-making", Ethics and Social Welfare, Vol. 11 No. 4, pp. 320-335.

Braye, S. and Preston-Shoot, M. (2017), Learning from SARS; a report for the London Safeguarding Adult Board, London, ADASS, available at: http://londonadass.org.uk (accessed $10^{\text {th }}$ Dec 2018).

British Association of Social Workers (BASW) (2018), Professional Capabilities framework for Social Work England Level descriptors for the four pre-qualifying levels and ASYE, Birmingham, BASW.

Burton, V. and Revell, L. (2018), "Professional Curiosity in Child Protection: Thinking the Unthinkable in a Neo-Liberal World", The British Journal of Social Work, Vol. 48 No. 6, pp. 15081523, https://doi.org/10.1093/bjsw/bcx123.

Carnwell, R. and Carson, A. (2009), The concepts of partnership and collaboration. In Carnwell, R. and Buchanan, J. (Eds) Effective Practice in health Social care and Criminal Justice: A Partnership Approach, $2^{\text {nd }}$ Edition, Berkshire, Open University Press, pp. 3-12.

Chapman, P. (2017), Safeguarding Adult Review Overview Report Adult A, Lancashire 
Safeguarding Adults Board, Preston.

Chisnell, C. and Kelly, C. (2019), Safeguarding in Social Work Practice: A Lifespan Approach, London, Sage/Learning Matters

Cooper, A. (2018), Partnership working and effectiveness in adult safeguarding, Seminar, Norfolk Safeguarding Adults Board, Norwich.

Cornish, S. and Preston-Shoot, M. (2013), "Governance in adult safeguarding in Scotland since the implementation of the Adult Support and Protection (Scotland) Act 2007", The Journal of Adult Protection, Vol. 15, No. 5, pp. 223-236.

Department of Health (DH) (2013), Statement of Government Policy on Adult Safeguarding, London, $\mathrm{DH}$

Department of Health and Social Care (DHSC) (2018), Post Qualifying Standards for Social Work Practice Supervisors in Adult Social Care, London, DHSC.

Department of Health and Social Care (DHSC) (2018a), Care Act guidance: care and support statutory guidance available at: www.gov.uk/government/publications/care-act-statutoryguidance/care-and-support-statutory-guidance (accessed on 1 October 2018).

Flynn, M. (2016), The death of 'Tom' A Serious Case Review, Somerset Safeguarding Adults Board, Taunton.

Flynn, M. (2018), Mendip House Safeguarding Adults Review, Somerset Safeguarding Adults Board, Taunton.

Georgiou, N. (2014), Orchid view Serious Case Review, West Sussex Adult Safeguarding Board, Worthing.

Hafford-Letchfield, T. and Carr, S. (2017), Promoting Safeguarding: Self-determination, Involvement and Engagement in Adult Safeguarding, in Cooper, A and White, E (Eds) Safeguarding Adults Under the Care Act 2014, London, Jessica Kingsley Publishers, pp. 91-108.

Haringey Safeguarding Children Board, (2009), Serious Case Review: Baby Peter, Executive Summary available at

http://www.haringeylscb.org/sites/haringeylscb/files/executive summary peter final.pdf (accessed 14 June 2019).

Julian, G. and Penhale, B. (2009), Safety matters: developing practice in safeguarding adults, Dartington, Research in practice for adults.

Kashdan, T., B., Sherman, R., A., Yarbro, J., and Funder, D. (2013), “How are curious people viewed and how do they behave in social situations? From the perspectives of self, friends, parents, and unacquainted observers", Journal of Personality, Vol. 81, pp. 142-154.

Kedge, S and Appleby, B. (2009), "Promoting a culture of curiosity within nursing practice", British 
Journal of Nursing, Vol. 18, 10, pp. 635-637.

https://doi.org/10.12968/bjon.2009.18.10.42485.

Laming, W., H. (2003), The Victoria Climbie Inquiry: report of an inquiry, London, The Stationery Office.

Lawson, J. (2017), The 'Making Safeguarding Personal' Approach to Practice, in Cooper, A. and White, E. (Eds) Safeguarding Adults Under the Care Act 2014, London, Jessica Kingsley Publishers, pp. 20-39.

Litman, J., A. (2005), "Curiosity and the pleasures of learning: Wanting and liking new information." Cognition and Emotion, Vol. 19, pp. 793-814.

Manchester Safeguarding Adults Board (2018), Professional curiosity and challenge - resources for practitioners, available at https://www.manchestersafeguardingboards.co.uk/resource/professional-curiosityresources-practitioners/ (accessed on 14 June 2019).

Mantell, A., R. and Jennings, M. (2016), Nosey Parkers? Professional curiosity in nursing and social work. Paper presented at Network for Psychiatric Nursing Research NPNR conference 2016, Nottingham, 15 - 16 September 2016, London, South Bank University.

Manthorpe, J., and Martineau, S. (2016), Serious Case Reviews into Dementia Care: An Analysis of Context and Content. The British Journal of Social Work, Volume 46, Issue 2, p. 514531, https://doi.org/10.1093/bjsw/bcu135.

Manthorpe, J., and Martineau, S. (2017), "Pressure points: learning from Serious Case Reviews of failures of care and pressure ulcer problems in care homes", The Journal of Adult Protection, Vol. 19 No. 5, pp. 284-296.

Mellor, D. (Undated), Adult C, The response of partner agencies to self-neglect, South Tyneside Safeguarding Adults Board, available file:///C:/Users/User/Downloads/SAR Case C South Tyneside Exec Summary .pdf (accessed $4^{\text {th }}$ Nov 2018).

Morgan, P. (2017), A response to “A preventable death? A family's perspective on an adult safeguarding review regarding an adult with traumatic brain injury", The Journal of Adult Protection, Vol. 19 Issue: 1, pp.4-9 .

Ohdedar, D. (2017), Overview Report - Executive summary safeguarding adults review: Significant incident learning process Adult $H$, Nottinghamshire Safeguarding Adults Board , West Bridgford.

Pearce, P. (2018), Kent and Medway Safeguarding Adults Board Safeguarding Adults Review: Beryl Simpson, Kent. 
Penhale, B., Perkins, L., Pinkney, L., Reid, D., Hussein, S. and Manthorpe, J. (2007), Partnership and Regulation in Adult Protection: The effectiveness of multi-agency working and the regulatory framework in Adult Protection. Final Report, Sheffield, University of Sheffield.

Perkins, N., Penhale, P., Reid, D., Pinkney, L., Hussein, S. and Manthorpe, J. (2007), Partnership means protection? Perceptions of the effectiveness of multi-agency working and the regulatory framework within adult protection in England and Wales, The Journal of Adult Protection, Vol. 9, No. 3 pp. $9-23$.

Petch, A. (2008), "Safety Matters: The Role of Partnership Working in Safeguarding Adults", Journal of Integrated Care, Vol. 16 No. 6, pp. 39-40

Peterson, C. and Seligman, M., E., P. (2004), Character strengths and virtues: A handbook and Classification, Oxford, Oxford University Press, ISBN 0-19-516701-5.

Phillips, C. (2016), "Wales' safeguarding policy and practice: a critical analysis", The Journal of Adult Protection, Vol. 18 1, pp.14-27, https://doi.org/10.1108/JAP-06-2015-0017.

Preston-Shoot, M. (2017), What difference does legislation make? Adult safeguarding through the lens of serious case reviews and safeguarding adult reviews. A report for south west region safeguarding adults boards, available at: http://ssab.safeguardingsomerset.org.uk/wpcontent/uploads/SW-SCRs-SARs-Report-Final-Version-2017.pdf (accessed 2nd Dec 2018).

Romeo, L. (2018), Clear standards for high quality adult social work, available at: https://lynromeo.blog.gov.uk/2018/12/11/clear-standards-for-high-quality-adult-socialwork/ (accessed 19th July 2019).

Sekerka, L., E., Godwin L., N. and Charnigo, R. (2014), "Motivating managers to develop their moral curiosity", Journal of Management Development, Vol. 33 No. 7, pp. 709-722.

Social Care Institute for Excellence (2017), Asset-based places, A model for development, available at: https://www.scie.org.uk/future-of-care/asset-based-places/case-studies/threeconversations (accessed 9 August 2019).

Solihull Safeguarding Adults Board (2017), Safeguarding Adult Review Report John, available at: https://ssab.org.uk/media/upload/about document/John\%20SAR\%20Final\%20Report\%202 017.pdf (accessed 2nd Dec 2018).

Stevens, E. (2013), Safeguarding vulnerable adults: exploring the challenges to best practice across multi-agency settings, The Journal of Adult Protection, Vol. 15 No. 2, pp. 85-95.

Stevens, M., Martineau, S., Norrie, C. and Manthorpe, J. (2017), Helping or hindering in adult safeguarding: an investigation of practice, London, The Social Care Workforce Research Unit (SCWRU) Kings College.

Thacker, H. (2018), Professional curiosity guidance, Norfolk Safeguarding Adult Board. 
Available at:

https://www.norfolksafeguardingadultsboard.info/assets/NSAB-GUIDANCE/NSAB-

Professional-Curiosity-Partnership-VersionSEPT2018FINAL02.pdf (accessed 1 Nov 2018).

Williams, D., P. and Chisholm, T. (2018), "Reflections on a serious case review: how health recommendations have changed since 2011 and the impact of professional curiosity on health assessments Adoption \& Fostering, Vol. 42 issue 2, pp: 201-205.

Wood, T. (2017), The Death of Lee Irving Safeguarding Adults Review, Newcastle Safeguarding Adults Board, Newcastle upon Tyne. 